Imagem

\title{
Ecocardiografia Tridimensional em Tempo Real da Valva Mitral em Paciente com Estenose Valvar Submetido a Valvoplastia com Cateter Balão
}

\author{
Marcelo L. C. Vieira, J osé L. Andrade, Wilson MathiasJ r., Samira S. Morhy, Luis F. Cardoso, \\ LuisJ. Kajita, J osé A. F. Ramires \\ São Paulo, SP
}

0 ecocardiograma transtorácico tridimensional em tempo real foi, recentemente, desenvolvido como método de avaliação da anatomia cardíaca ${ }^{1,2}$. Descrevemos caso de homem de 32 anos, apresentando história pregressa de doença reumática, submetido a valvoplastia mitral com o emprego de cateter balão pela técni-

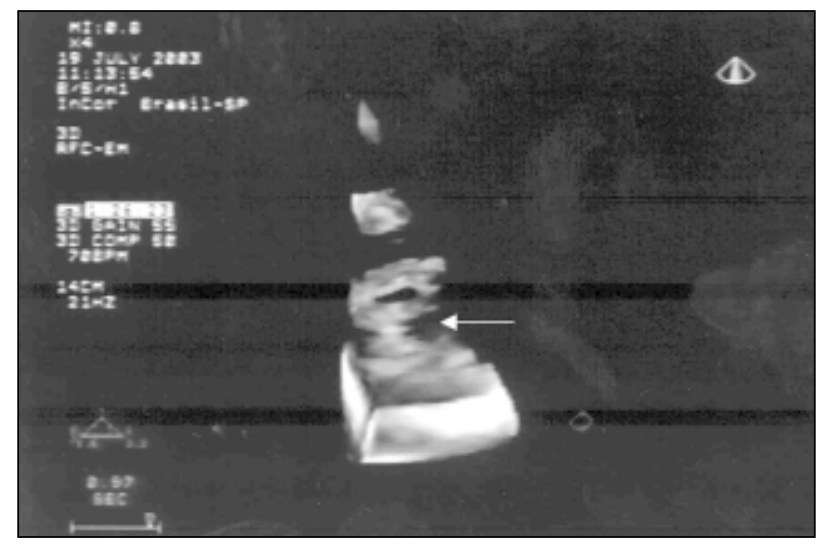

Fig. 1 - Ecocardiograma transtorácico tridimensional em tempo real, projeção transversal, visão do ventrículo esquerdo para oátrio esquerdo, pré valvoplastia mitral. Área valvar mitral: $0,82 \mathrm{~cm}^{2}$. Valva mitral (seta).

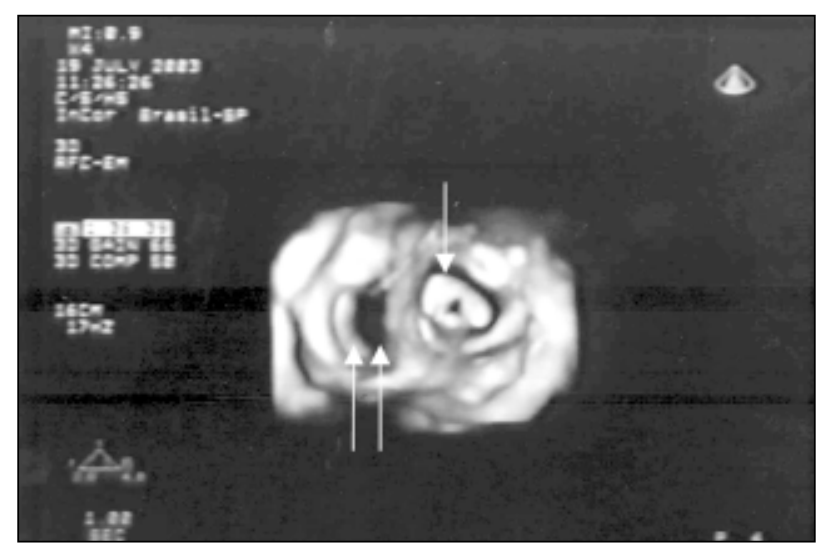

Fig. 2 - Ecocardiograma transtorácico tridimensional em tempo real, projeção apical, visão do ventrículo esquerdo para o átrio esquerdo, pré valvoplastia mitral. Valva mitral (seta). Valva tricúspide (seta dupla). ca de Inoue. 0 paciente apresentava estenose valvar mitral importante (figs. 1, 2), e sinais e sintomas de insuficiência cardíaca classe funcional III (NYHA). A valvoplastia mitral foi realizada com sucesso (figs. 3,4 ), sem complicações, tendo o paciente recebido alta hospitalar 2 dias após o procedimento.

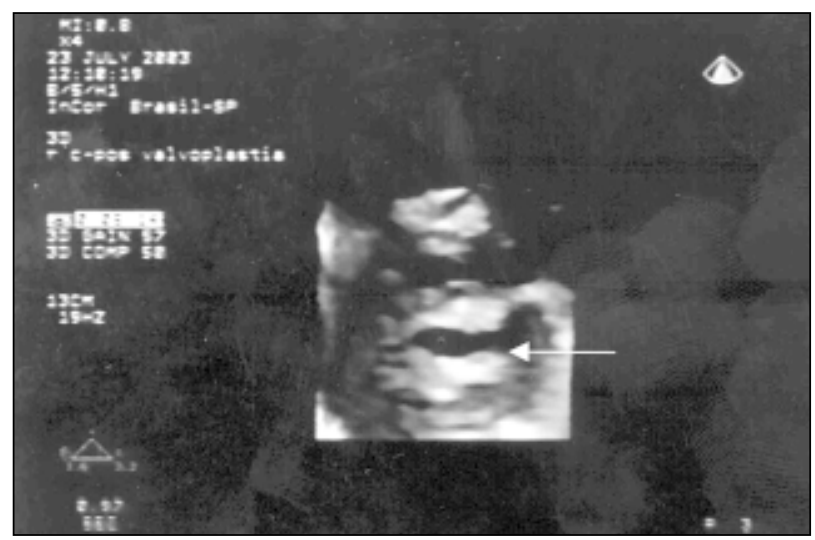

Fig. 3 - Ecocardiograma transtorácico tridimensional em tempo real, projeção transversal, visão do ventrículo esquerdo para o átrio esquerdo, pós valvoplastia mitral. Área valvar mitral: 1,62 cm². Abertura da comissura valvar mitral ântero-lateral (seta).

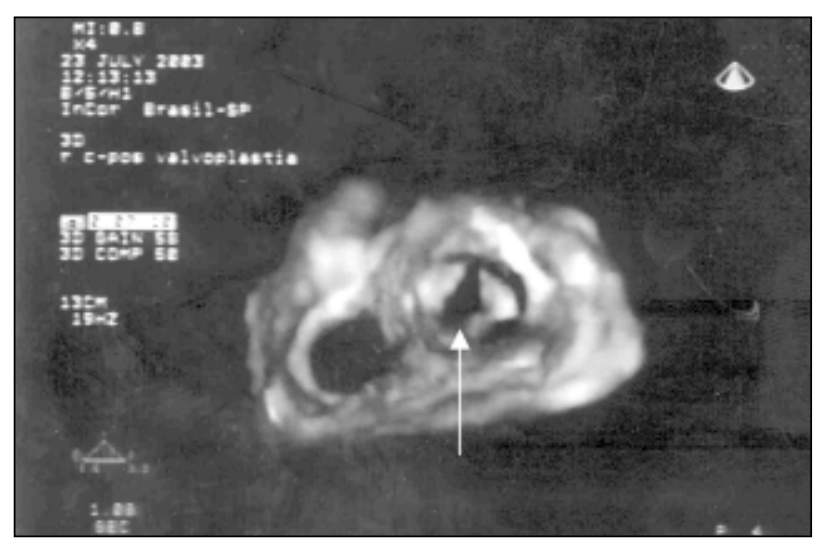

Fig. 4 - Ecocardiograma transtorácico tridimensional em tempo real, projeção apical, visão do ventrículo esquerdo para o átrio esquerdo, pós valvoplastia mitral demonstrando abertura da comissura valvar mitral ântero-lateral (seta). 
Referências

1. Singh V, Nanda NC, Agrawal G, et al. Live three-dimensional echocardiographic assessment of mitral stenosis. Echocardiography. 2003; 20: 743-54.
2. Kwan J, Shiota T, Agler DA, et al. Geometric differences of the mitral apparatus between ischemic and dilated cardyomyopathy with significant mitral regurgitation: realtime three-dimensional echocardiography study. Circulation. 2003; 107: 1135-40. 